\title{
Collision-free photochemistry of methylazide: Observation of unimolecular decomposition of singlet methylnitrene
}

\author{
Christopher Larson, ${ }^{\text {a) }}$ Yuanyuan Ji, Petros Samartzis, and Alec M. Wodtke \\ Department of Chemistry and Biochemistry, University of California, Santa Barbara, Santa Barbara, \\ California 93106 \\ Shih-Huang Lee \\ National Synchrotron Radiation Research Center, 101 Hsin-Ann Road, Science-Based Industrial Park, \\ Hsinchu 30077, Taiwan, Republic of China \\ Jim Jr-Min Lin, Chanchal Chaudhuri, and Tao-Tsung Ching \\ Institute of Atomic and Molecular Sciences, Academia Sinica, P.O. Box 23-166, Taipei 106, Taiwan, \\ Republic of China
}

(Received 17 April 2006; accepted 24 May 2006; published online 2 October 2006)

\begin{abstract}
Methylazide photolysis at $248 \mathrm{~nm}$ has been investigated by ionizing photofragments with synchrotron radiation in a photofragmentation translational spectroscopy study. $\mathrm{CH}_{3} \mathrm{~N}$ and $\mathrm{N}_{2}$ were the only observed primary products. The translational energy release suggests a simple bond rupture mechanism forming singlet methylnitrene, ${ }^{1} \mathrm{CH}_{3} \mathrm{~N}$, and $\mathrm{N}_{2}$. Thus, these experiments reveal the unimolecular decomposition of this highly unstable species. We explain our observations through a mechanism which is initiated by the isomerization of ${ }^{1} \mathrm{CH}_{3} \mathrm{~N}$ to a highly internally excited methanimine $\mathrm{H}_{2} \mathrm{C}=\mathrm{NH}$ isomer, which decomposes by $1,1-\mathrm{H}_{2}$ elimination forming $\mathrm{HNC}+\mathrm{H}_{2}$ as well as sequential $\mathrm{H}$-atom loss ( $\mathrm{N}-\mathrm{H}$ followed by $\mathrm{C}-\mathrm{H}$ bond cleavage), to form $\mathrm{HCN}$. No evidence for dynamics on the triplet manifold of surfaces is found. () 2006 American Institute of Physics.

[DOI: $10.1063 / 1.2215598$ ]
\end{abstract}

\section{INTRODUCTION}

Despite its chemical simplicity, the ultraviolet (UV) photochemistry of methylazide, $\mathrm{H}_{3} \mathrm{C}-\mathrm{N}-\mathrm{N} \equiv \mathrm{N}$, has not been extensively studied and remains poorly understood. ${ }^{1-3}$ The electronic spectrum of methylazide has two absorption maxima-a weak peak at $286 \mathrm{~nm}$ and a strong peak at $215 \mathrm{~nm} .{ }^{4} \mathrm{C}-\mathrm{N}$ bond rupture forming $\mathrm{CH}_{3}+\mathrm{N}_{3}$,

$$
\mathrm{H}_{3} \mathrm{C}-\mathrm{N}-\mathrm{N} \equiv \mathrm{N} \rightarrow \mathrm{H}_{3} \mathrm{C}+\mathrm{N}_{3} \text {, }
$$

is energetically accessible ${ }^{5,6}$ at wavelengths shorter than $490 \mathrm{~nm}$ but has never been observed. UV emission spectra of triplet methylnitrene, ${ }^{3} \mathrm{CH}_{3} \mathrm{~N}$, resulting from the UV photolysis of methylazide $\left(\lambda_{\text {photolysis }} \sim 292-325 \mathrm{~nm}\right)$ have been reported ${ }^{2}$ and taken as indirect evidence for the formation of singlet methanimine, $\mathrm{H}_{2} \mathrm{C}=\mathrm{NH}$. Methanimine has been observed directly by cavity ring down spectroscopy in the pyrolysis of methylazide.

Despite this evidence it is not clear if either ${ }^{3} \mathrm{CH}_{3} \mathrm{~N}$ or $\mathrm{H}_{2} \mathrm{C}=\mathrm{NH}$ is a primary product of the $\mathrm{UV}$ photolysis of $\mathrm{CH}_{3} \mathrm{~N}_{3}$. A simple $\mathrm{N}-\mathrm{N}$ bond rupture mechanism,

$$
\mathrm{H}_{3} \mathrm{C}-\mathrm{N}-\mathrm{N} \equiv \mathrm{N} \rightarrow \mathrm{H}_{3} \mathrm{C}-\mathrm{N}+\mathrm{N}_{2},
$$

suggests the formation of spin-allowed singlet methylnitrene, ${ }^{1} \mathrm{CH}_{3} \mathrm{~N}$. Theoretical predictions of the energetics of ${ }^{1} \mathrm{CH}_{3} \mathrm{~N}$ indicate that it is energetically accessible at photolysis wavelengths shorter than $700 \mathrm{~nm} .^{8}$ In the $248 \mathrm{~nm}$ photolysis of methylazide, singlet methylnitrene would have

\footnotetext{
${ }^{a)}$ Electronic mail: clarson@chem.ucsb.edu
}

$75.5 \mathrm{kcal} / \mathrm{mol}$ available energy. Quantum chemical calculations at the multiconfiguration self-consistent field (MCSCF) level show that the barrier to $1,2-\mathrm{H}$-atom shift, $\mathrm{H}_{3} \mathrm{C}-\mathrm{N}$ $\rightarrow \mathrm{H}_{2} \mathrm{C}=\mathrm{NH}$, is lower than $2 \mathrm{kcal} / \mathrm{mol}$ suggesting perhaps that ${ }^{1} \mathrm{CH}_{3} \mathrm{~N}$ may have no barrier to isomerization and should not be thought of as an isolable chemical intermediate in the decomposition of methylazide. ${ }^{9}$ However, experimental evidence is available suggesting that the ${ }^{1} \mathrm{CH}_{3} \mathrm{~N}$ is stable, namely, electron photodetachment spectra of $\mathrm{CH}_{3} \mathrm{~N}^{-}$, which identified both $\widetilde{X}^{3} A_{2}$ and $\widetilde{a}^{1} E$ methylnitrene. ${ }^{10} \mathrm{CASPT} 2 \mathrm{cal}-$ culations with relatively large basis sets and zero point energy corrections report a calculated barrier to isomerization of $2.5 \pm 1.5 \mathrm{kcal} / \mathrm{mol} .{ }^{11}$ The authors conclude that ${ }^{1} \mathrm{CH}_{3} \mathrm{~N}$ is unequivocally an energy minimum with a barrier to rearrangement and express the hope that their calculations will inspire further studies to observe or chemically trap ${ }^{1} \mathrm{CH}_{3} \mathrm{~N}$.

Recent UV Raman experiments of dissociating molecules, which are designed to show vibrational modes activated by the forces of dissociation, ${ }^{12}$ have been applied to methylazide photodissociation at $313 \mathrm{~nm}$. ${ }^{1}$ In contrast to the above line of reasoning, these authors concluded that methanimine and molecular nitrogen are formed in a concerted mechanism involving simultaneous 1,2-H-atom transfer and $\mathrm{N}-\mathrm{N}$ bond cleavage,

$$
\mathrm{H}_{3} \mathrm{C}-\mathrm{N}-\mathrm{N} \equiv \mathrm{N} \rightarrow \mathrm{H}_{2} \mathrm{C}=\mathrm{N}-\mathrm{H}+\mathrm{N}_{2} \text {. }
$$

This mechanism is analogous to that reported by Bock and Dammel for methylazide pyrolysis (i.e., ground electronic state decomposition) where it is believed that the 1,2-H-atom shifts to form $\mathrm{CH}_{2} \mathrm{NH}$ in a concerted fashion with $\mathrm{N}_{2}$ 
elimination. ${ }^{13}$ In $248 \mathrm{~nm}$ photolysis of methylazide, methanimine would have $165.1 \mathrm{kcal} / \mathrm{mol}$ available energy. Ground singlet electronic state quantum chemistry calculations on methylazide dissociation have reported an $\sim 40 \mathrm{kcal} / \mathrm{mol}$ barrier consistent with this mechanism. ${ }^{8}$ More recently, however, Arenas et al. have found a singlet-triplet crossing lower than $40 \mathrm{kcal} / \mathrm{mol}$, which may represent the actual barrier to methylazide pyrolysis forming ${ }^{3} \mathrm{H}_{3} \mathrm{C}-\mathrm{N}$ $+\mathrm{N}_{2}$. This transition state corresponds to a simple bond rupture reaction. ${ }^{9}$

With these questions in mind, we set out to investigate UV methylazide photolysis under collision-free conditions using synchrotron radiation in photofragmentation translational energy spectroscopy. Since the available energy to the products ${ }^{1} \mathrm{CH}_{3} \mathrm{~N}+\mathrm{N}_{2}$ vs $\mathrm{H}_{2} \mathrm{C}=\mathrm{N}-\mathrm{H}+\mathrm{N}_{2}$ differs by around $90 \mathrm{kcal} / \mathrm{mol}$, we expected the translational energy release spectrum of the UV photofragments to be quite helpful in understanding the primary photochemical events in methylazide photolysis. We have recently obtained high quality data at $\lambda_{\text {photolysis }}=248,193$, and $157 \mathrm{~nm}$. Here we report the data and analysis of our $248 \mathrm{~nm}$ work. Note that $\lambda=248 \mathrm{~nm}$ falls in between the two absorption maxima for methylazide.

\section{EXPERIMENT}

Methylazide was synthesized through the reaction of sodium azide with methyl iodide in a 4:1 dimethyl formamide(DMF)/water solution. According to Bock and Dammel, ${ }^{13}$ alkyl azides can be synthesized from substitution reactions with halogen derivatives. Methyl iodide was used instead of the more common dimethyl sulfate due to safety consideration. The mixture was stirred and heated in a nitrogen environment to $90{ }^{\circ} \mathrm{C}$ for several hours. The gaseous product passed through a short water-jacketed condenser, and liquid methylazide was collected in a flask submerged in a dry ice/acetone bath. The product was determined, through NMR, ${ }^{14}$ to contain methylazide with some methyl iodide contaminant.

The experiments were carried out at the Chemical Dynamics Beamline 21A at the National Synchrotron Radiation Research Center in Hsinchu, Taiwan. The machine has been described elsewhere ${ }^{15}$ and only a brief overview of essential components will be presented here. Liquid methylazide samples were placed in a glass bubbler and kept at $-15^{\circ} \mathrm{C}$, which corresponds to a vapor pressure of $\sim 150$ Torr for our sample. Helium carrier gas was passed through the liquid and the total backing pressure entering the source chamber averaged 260 Torr during this experiment for a mixture which is about $60 \%$ methylazide. The machine uses a rotating source chamber with a fixed detector. For this experiment, the detector was at a $30^{\circ}$ angle from the source. A molecular beam was generated by a solenoid pulse valve (an Even-Lavie Valve, low repetition rate $^{16}$ ) and the beam was intersected at $90^{\circ}$ by an unpolarized, focused $[8.5$ $\times 2.5 \mathrm{~mm}^{2}$ with laser spot size narrower in time of flight (TOF) direction] $248 \mathrm{~nm} \mathrm{KrF}$ excimer laser beam. The resulting photofragments were ionized by synchrotron radiation at a right angle after a $10.05 \mathrm{~cm}$ flight distance and mass selected by a quadrupole before reaching the detector. Most data were averaged over 20 000-80 000 laser shots.

Experiments could be carried out at various photoionization energies $\left(h \nu_{\text {photoionization }}\right)$ by changing the gap of the beamline undulator. Experiments reported here were performed at $h \nu_{\text {photoionization }}=17.05,13.3$, and $11.9 \mathrm{eV}$. The resolution of the ionizing radiation was about $3 \%$ or $\pm 0.15 \mathrm{eV}$. The dependence of the signals on $h \nu_{\text {photoionization was very }}$ helpful in distinguishing isomers (HNC vs HCN) and coincident $m / z$ values $\left(\mathrm{N}_{2}\right.$ vs $\left.\mathrm{CH}_{2} \mathrm{~N}\right)$.

The data obtained in this experiment were analyzed using two computer programs, both employing the forward convolution approach, known to be able to simulate experimental conditions with highest accuracy. The first program, PHOTRAN, simulates a time of flight spectrum based on an input translational energy probability distribution $P\left(E_{T}\right)$ and accurate information about all of the aspects of the experiment, including molecular beam velocity and angular distribution, detector flight length, sizes of laser and ionization volumes, detector angular acceptance width, and several others. $P\left(E_{T}\right)$ is adjusted until the simulated spectrum matches the experimental data. The other program, capable of performing similar calculations for secondary dissociation products using a brute-force forward convolution method, is ANALMAX. ${ }^{17}$ For both the primary and secondary dissociations, we used an anisotropy parameter $\beta=0$, corresponding to an isotropic distribution.

\section{RESULTS}

The $248 \mathrm{~nm}$ photolysis of molecular beams formed from our methylazide samples showed detectable signals at $\mathrm{m} / \mathrm{z}$ values of $29\left(\mathrm{CH}_{2} \mathrm{HN}^{+}\right), 28\left(\mathrm{~N}_{2}^{+}\right.$and $\left.\mathrm{CH}_{2} \mathrm{~N}^{+}\right), 27\left(\mathrm{HCN}^{+}\right.$and $\left.\mathrm{HNC}^{+}\right), 15\left(\mathrm{CH}_{3}^{+}\right)$, and $14\left(\mathrm{CH}_{2}^{+}\right)$. The methyl iodide impurities were responsible for the signals at $m / z=14$ and 15 , which were unambiguously determined by fitting the observed TOF spectrum at $m / z=15$ with a previously reported translational energy distribution for methyl iodide photolysis at $248 \mathrm{~nm}$. ${ }^{18}$ The $\mathrm{CH}_{3}^{+}$TOF spectrum consisted of two narrow peaks that are characteristic of methyl fragments formed with the corresponding iodine atom in two spin states $\left({ }^{2} P_{3 / 2}\right.$ and $\left.{ }^{2} P_{1 / 2}\right)$. The $m / z=14$ TOF spectrum was nearly identical to that of $m / z=15$ and was assigned to a small amount of dissociative ionization of $\mathrm{CH}_{3}$ forming $\mathrm{CH}_{2}^{+}$resulting from the high-energy synchrotron radiation. The threshold for dissociative ionization for $\mathrm{CH}_{3}$ to $\mathrm{CH}_{2}^{+}$is $15.09 \mathrm{eV},{ }^{19}$ and our ionization photons were $17.05 \mathrm{eV}$. It is also noteworthy that we could not observe signal at $m / z=42\left(\mathrm{~N}_{3}^{+}\right)$, which would be the partner fragment for a methyl resulting from methylazide, reaction (R1). Thus we find no evidence of reaction (R1) in this work.

Figure 1 shows the TOF spectra obtained at $m / z=29$ and 28 with a photoionization energy of $17.05 \mathrm{eV}$. Here, the synchrotron produces photons that are energetic enough to ionize every possible reaction product including $\mathrm{N}_{2}$ and $\mathrm{CH}_{2} \mathrm{NH}$. The filled squares in Fig. 1 show the data after they have been normalized to laser power, number of laser shots (passes), and synchrotron current. A constant background 


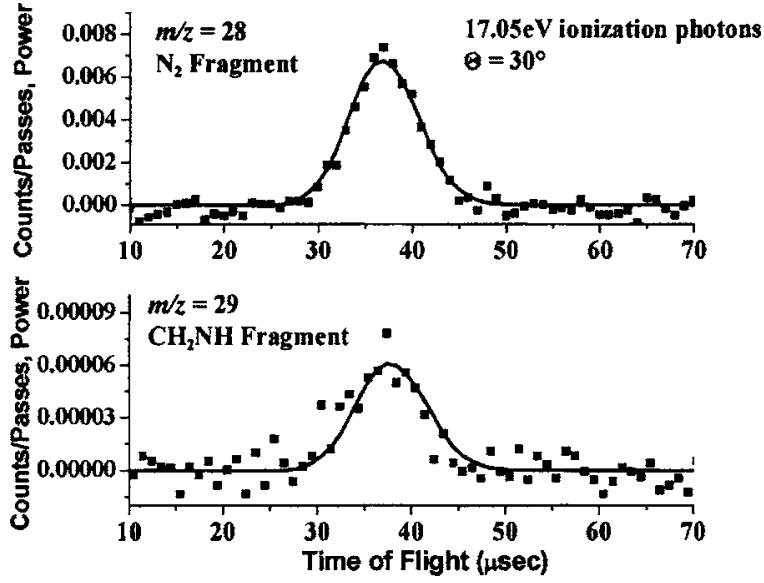

FIG. 1. Top: Time of fight spectra of $m / z=28$ with $17.05 \mathrm{eV}$ ionization photons and detector angle $30^{\circ}$ from molecular beam. Bottom: Time of flight spectra of $m / z=29$ with the same parameters. The solid line in both spectra is the fit from PHOTRAN using the same translational energy release distribution. The $y$-axis scale has been normalized for the number of laser shots, laser power, and synchrotron light intensity.

value has also been subtracted from every data point. The solid lines shown in Fig. 1 are the forward convolution simulations from PHOTRAN derived from a single $P\left(E_{T}\right)$, Fig. 2, indicating that the products observed at $m / z=28$ and 29 are "momentum matched." We thus attribute these fragments to an $\mathrm{N}_{2}$ loss channel. The $P\left(E_{T}\right)$ of Fig. 2 shows remarkably little energy appearing in the relative translational motion of the reaction products, $\bar{E}_{T} \sim 25 \mathrm{kcal} / \mathrm{mol}$. If reaction $(\mathrm{R} 3)$ were important, the concerted formation of methanimine and $\mathrm{N}_{2}$, we must rationalize why only $12 \%$ of the available energy appears as translation. Of course this is straightforward to understand if we pursue the simpler explanation, that singlet methylnitrene is the primary product of the photochemistry at $248 \mathrm{~nm}$, reaction (R2).

Following this approach, ${ }^{1} \mathrm{CH}_{3} \mathrm{~N}$ is clearly formed with sufficient internal energy to isomerize to the more stable $\mathrm{CH}_{2} \mathrm{NH}$ isomer on a subpicosecond time scale, gaining $\sim 90 \mathrm{kcal} / \mathrm{mol}$ internal energy in the process to reach a total of $\sim 120 \mathrm{kcal} / \mathrm{mol}$ internal energy. Products are seen to re-

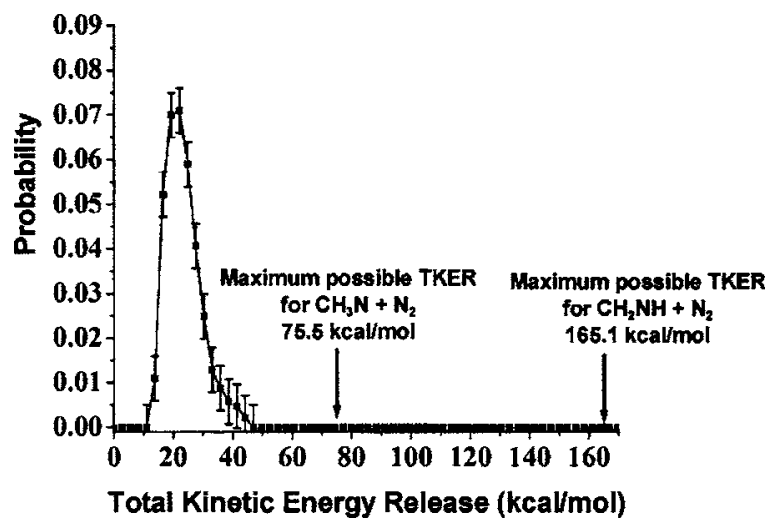

FIG. 2. Translational energy release distribution for $\mathrm{CH}_{3} \mathrm{~N}_{3} \rightarrow \mathrm{CH}_{3} \mathrm{~N}+\mathrm{N}_{2}$ channel. Both spectra in Fig. 1 have been fitted with this distribution. The maximum possible energy release if all energy goes into translation for the channels $\mathrm{CH}_{3} \mathrm{~N}+\mathrm{N}_{2}$ and $\mathrm{CH}_{2} \mathrm{NH}+\mathrm{N}_{2}$ have been marked. The error bars were determined by varying the input distribution until PHOTRAN no longer gave an acceptable fitting.

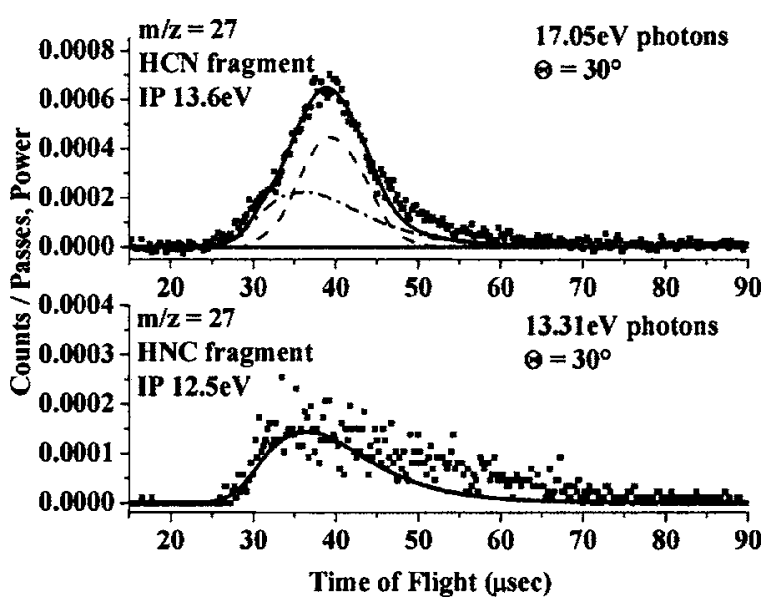

FIG. 3. Top: $m / z=27$ fragment time of flight spectra with $17.05 \mathrm{eV}$ ionization photons. The solid line in both spectra is the fit determined by using the ANALMAX secondary dissociation analysis program. The dash-dotted line shows the contribution to the total fit from the HNC fragment energy distribution and the dashed line shows the contribution from the HCN fragment energy distribution. Bottom: $m / z=27$ fragment time of flight spectra with $13.31 \mathrm{eV}$ ionization photons. The $y$-axis scale has been normalized for the number of laser shots, laser power, and synchrotron light intensity.

sult from several unimolecular dissociation processes that occur from the highly internally excited methanimine. Despite the significant amount of dissociation, the $m / z=29$ signal is still momentum matched to $m / z=28$. This suggests that the secondary dissociation probability is independent of the translational energy. Figure 3 shows TOF spectra recorded at $m / z=27$ at two different values of $h \nu_{\text {photoionization. }}$ This allows us to distinguish between the two isomers HNC [ionization potential (IP) $=12.5 \mathrm{eV}$ (Ref. 20)] and HCN [IP $=13.6 \mathrm{eV}$ (Ref. 21)]. In the upper panel we employed $h \nu_{\text {photoionization }}=17.05 \mathrm{eV}$, and two (a fast and a slow) components are seen. Whereas, in the lower panel $\left(h \nu_{\text {photoionization }}=13.3 \mathrm{eV}\right.$, which is less than the IP of $\left.\mathrm{HCN}\right)$ only the fast component is detectable. Thus we can immediately identify the fast component as HNC and the slow component as HCN. Moreover, they are clearly formed by different processes and are not the result of the isomeric interconversion of $\mathrm{HNC} \leftrightarrow \mathrm{HCN}$ as has been previously suggested. ${ }^{8}$ Indeed, our ability to distinguish the two isomers by photoionization wavelength shows that the isomeric interconversion of $\mathrm{HNC} \leftrightarrow \mathrm{HCN}$ is unimportant under our conditions. We would also like to point out that the forward convolution fit from ANALMAX is not perfect on the slower tail of the lower panel of Fig. 3. This could be due to a small contribution of $\mathrm{HCN}$ ionization (from vibrationally excited molecules) that cannot be fully resolved by the wavelength dependent near threshold photoionization. We will return to the fitting of these data shortly.

Figure 4 shows the TOF spectrum (filled squares) of $m / z=28$ at $h \nu_{\text {photoionization }}=11.91 \mathrm{eV}, 3.5 \mathrm{eV}$ below the IP of $\mathrm{N}_{2}$. The most likely explanation for this signal is that we are observing a daughter ion of the ionized $\mathrm{CH}_{2} \mathrm{NH}$ fragments by the following mechanism:

$$
\mathrm{H}_{2} \mathrm{C}=\mathrm{NH}^{+} \rightarrow \mathrm{H}_{2} \mathrm{C}=\mathrm{N}^{+}+\mathrm{H} .
$$

Normally, we would not invoke such an explanation since vacuum ultraviolet (vuv) synchrotron photoionization is nor- 


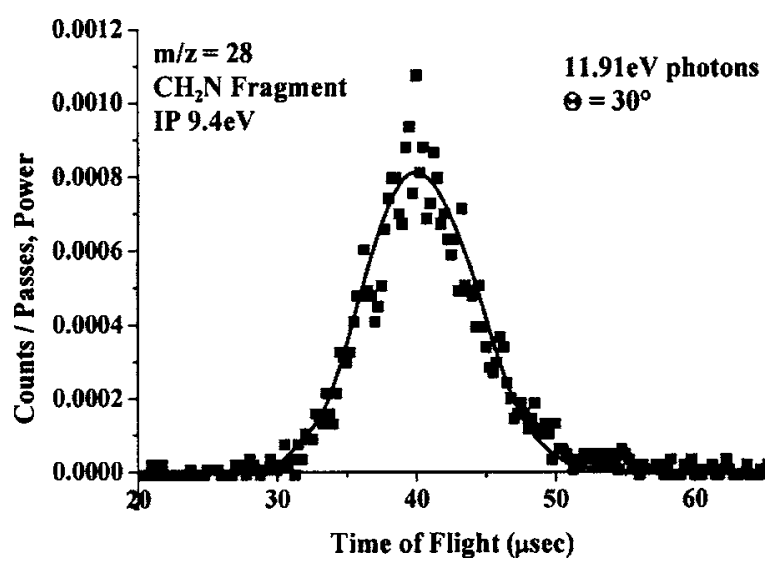

FIG. 4. $m / z=28$ fragment time of flight spectra with $11.91 \mathrm{eV}$ ionization energy photons. The solid line is the fit from analmax. This fit was created using an essentially zero kinetic energy release distribution for the secondary release and the distribution in Fig. 2 for the primary release.

mally used to suppress ion fragmentation. However, the observed translational energies of the neutral $\mathrm{CH}_{2} \mathrm{NH}$ in this work are sufficiently low, offering the implication that the $\mathrm{CH}_{2} \mathrm{NH}$ fragment is formed with large internal energies and that dissociative ionization may be important. It is worth mentioning that we cannot rule out that the observed $\mathrm{H}_{2} \mathrm{CN}^{+}$ comes from the intermediate step in the formation of $\mathrm{HCN}$ by the sequential loss of hydrogen atoms as shown by the following reaction:

$$
\mathrm{H}_{2} \mathrm{C}=\mathrm{NH} \rightarrow \mathrm{H}_{2} \mathrm{C}=\mathrm{N}+\mathrm{H} .
$$

The solid line fit to the data is the result of the forward convolution simulation of the primary [using the $P\left(E_{T}\right)$ of Fig. 2] and secondary [using an essentially zero kinetic energy release $P\left(E_{T}\right)$ ] dissociation pathways using ANALMAX. As there is no kinetic energy release for the secondary dissociation (R4), we cannot clearly distinguish between a daughter ion and the secondary product. Given all this, we consider it most likely that the observed signal is due to the daughter ion of ionized methanimine.

Fitting the $m / z=27$ of Fig. 3 can now be described. Consider first the lower panel. We assign this TOF spectrum to $\mathrm{HNC}$ formed by $1,1-\mathrm{H}_{2}$ elimination from methanimine, reaction (R5),

$$
\mathrm{H}_{2} \mathrm{C}=\mathrm{N}-\mathrm{H} \rightarrow \mathrm{H}_{2}+\mathrm{C} \equiv \mathrm{N}-\mathrm{H} .
$$

The ANALMAX program was used to simulate primary, using the $P\left(E_{T}\right)$ of Fig. 2, and secondary dissociations, using the $P\left(E_{T}\right)$ from Fig. 5. The relatively large translational energy release (up to $30 \mathrm{kcal} / \mathrm{mol}$ ) for reaction (R5) is consistent with the molecular elimination of closed shell reactants forming closed shell products.

The upper panel of Fig. 3 is assigned to $\mathrm{HCN}$ formed by sequential $\mathrm{H}$-atom elimination from methanimine,

$$
\begin{aligned}
& \mathrm{H}_{2} \mathrm{C}=\mathrm{NH} \rightarrow \mathrm{H}_{2} \mathrm{C}=\mathrm{N}+\mathrm{H}, \\
& \mathrm{H}_{2} \mathrm{C}=\mathrm{N} \rightarrow \mathrm{HC} \equiv \mathrm{N}+\mathrm{H} .
\end{aligned}
$$

The fit to the slow component of the upper panel of Fig. 3 was obtained from the same fitting analysis described for reaction (R4). The ANALMAX program (nor any other to our

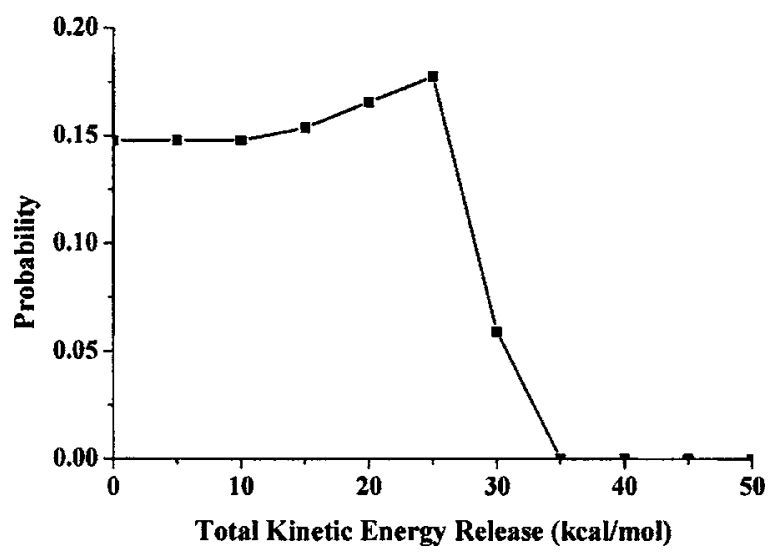

FIG. 5. Translational energy release distribution for the HNC fit shown in Fig. 2. This energy distribution was determined using ANALMAX.

knowledge) is not capable of modeling tertiary dissociation. Thus our fitting of the slow component of the $m / z=27$ TOF, with the same primary plus secondary model that fits the $m / z=28$ TOF spectrum of Fig. 4, is tantamount to assuming that the $P\left(E_{T}\right)$ for reaction (R6) peaks sharply near zero. This assumption is likely not rigorously correct; however, the light mass of the departing $\mathrm{H}$ atom means that the data is not sensitive to relatively large deviations from this assumption.

To summarize our results on the microscopic decomposition mechanism for the $248 \mathrm{~nm}$ photolysis of methylazide, we present the following table of conclusions:

Initiation

$$
\begin{array}{r}
\mathrm{H}_{3} \mathrm{C}-\mathrm{N}-\mathrm{N} \equiv \mathrm{N} \rightarrow \mathrm{H}_{3} \mathrm{C}-\mathrm{N}+\mathrm{N}_{2} \\
\quad(\text { simple bond rupture) } \\
\mathrm{H}_{3} \mathrm{C}-\mathrm{N}+\mathrm{N}_{2} \rightarrow \mathrm{H}_{2} \mathrm{C}=\mathrm{NH}+\mathrm{N}_{2} \quad \text { (isomerization), }
\end{array}
$$

\section{HCN formation}

$$
\begin{aligned}
& \mathrm{H}_{2} \mathrm{C}=\mathrm{NH} \rightarrow \mathrm{H}_{2} \mathrm{C}=\mathrm{N}+\mathrm{H} \text { (simple bond rupture) } \\
& \mathrm{H}_{2} \mathrm{C}=\mathrm{N} \rightarrow \mathrm{HC} \equiv \mathrm{N}+\mathrm{H} \quad \text { (simple bond rupture), }
\end{aligned}
$$

HNC formation

$$
\mathrm{H}_{2} \mathrm{C}=\mathrm{N}-\mathrm{H} \rightarrow \mathrm{H}_{2}+\mathrm{C} \equiv \mathrm{N}-\mathrm{H}\left(1,1 \mathrm{H}_{2}\right. \text { elimination). }
$$

\section{DISCUSSION}

A chart of the relevant energetics is shown in Fig. 6. This figure shows selected points on the two lowest potential energy surfaces of methylazide, collecting results shown in several figures of the work of Nguyen et al. including heats of formation and exit barriers. ${ }^{8}$ Here, points on the singlet potential energy surface are shown, connected by solid lines. Points on the lowest triplet potential energy surface are shown, connected by dashed lines. The available energy after $248 \mathrm{~nm}$ photolysis is shown as a horizontal dashed line. The photolysis photon energy is indicated by an arrow labeled $h \nu$. 


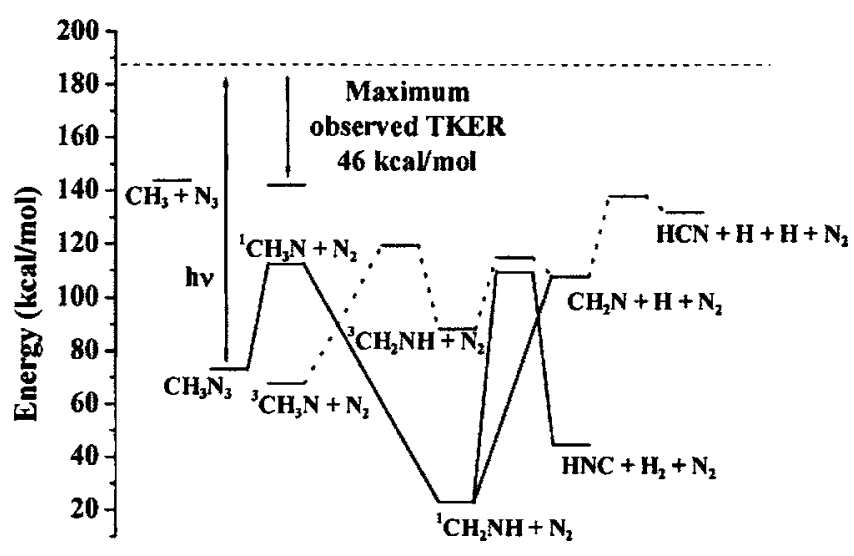

FIG. 6. Schematic of the energies for relevant processes in the methylazide photodissociation, obtained from the calculations of Nguyen et al. ${ }^{8}$ except for the $\mathrm{CH}_{3}+\mathrm{N}_{3}$ channel, which was calculated from heats of formation (Refs. 5 and 6). The singlet manifold is represented with a solid line and the triplet manifold is shown with a dashed line. Unlabeled lines represent a barrier for that process. Energies are shown as heats of formation at $0 \mathrm{~K}$.

The maximum observed translational energy release for the $\mathrm{N}_{2}$ elimination channel as determined from the forward convolution fitting is also shown. As mentioned above we believe that the remarkable characteristic of this photochemistry is the small fraction of available energy being channeled into the relative translation of the products. If a concerted photodissociation mechanism [reaction (R3)] forming methanimine is operative, one must explain why only $\sim 12 \%$ of the available energy appears as translation.

$$
\mathrm{H}_{3} \mathrm{C}-\mathrm{N}-\mathrm{N} \equiv \mathrm{N} \rightarrow \mathrm{H}_{2} \mathrm{C}=\mathrm{N}-\mathrm{H}+\mathrm{N}_{2} .
$$

This is indeed counterintuitive. Such a postulated concerted mechanism suggests that electronic structure rearrangements take place so that the products, two closed shell molecules, ${ }^{1} \mathrm{H}_{2} \mathrm{C}=\mathrm{NH}$ and $\mathrm{N}_{2}$, will be initially formed within bonding distance of one another. The repulsive energy of such an interaction would certainly be expected to produce a substantial translational energy release. In an experimental example of two recoiling closed shell molecules, HONO elimination from nitroethane and 2-nitropropane, forming ethene and propene, respectively, $\sim 70 \%$ of the exit barrier energy was released into product translation. ${ }^{22}$ Likewise, molecular elimination from ethylacetate producing acetic acid and ethylene released more than $50 \%$ of the barrier height into translation. ${ }^{23}$ Consider, for example, the ground electronic singlet-state exit barrier calculated by Nguyen et al., which describes concerted decomposition to methanimine and $\mathrm{N}_{2}$, is more than $90 \mathrm{kcal} / \mathrm{mol}^{8}{ }^{8}$ Thus even for trajectories that started at the top of this barrier, it would be difficult to understand $\bar{E}_{T}=25 \mathrm{kcal} / \mathrm{mol}$. Furthermore, the available energy to form methanimine and $\mathrm{N}_{2}$ in the $248 \mathrm{~nm}$ photolysis of methylazide far exceeds the barrier height $E_{\text {ava }}$ $\sim 165 \mathrm{kcal} / \mathrm{mol}$.

On the other hand, the fact that little energy appears as translation can be quickly understood if the initially formed products are ${ }^{1} \mathrm{CH}_{3} \mathrm{~N}$ and $\mathrm{N}_{2}$, where more than $120 \mathrm{kcal} / \mathrm{mol}$ are initially tied up as potential energy associated with the unstable structure of the singlet methylnitrene. A "soft product impulse approximation" 24 also provides a useful model to further substantiate the ${ }^{1} \mathrm{CH}_{3} \mathrm{~N}+\mathrm{N}_{2}$ channel. In this approximation, the initial impulsive energy release between two atoms, which in our case are the two nitrogen atoms sharing the dissociating bond, is forced to obey linear momentum conservation. In addition, the linear momentum between the photofragments is also conserved. This model should work as a reasonable approximation for our system. For HONO $+\mathrm{C}_{2} \mathrm{H}_{4}$, with an impulse between the $\mathrm{C}$ and $\mathrm{N}$ atoms, $E_{T} / E_{\text {ava }}$ was found to be $\sim 0.4$. Using this same approximation for our methylazide system, $E_{T} / E_{\text {ava }}$ is calculated to be $\sim 0.49$. Within the context of (R2), this would give a translational energy of $37 \mathrm{kcal} / \mathrm{mol}$. From Fig. 2, the average translational energy is $29.0 \mathrm{kcal} / \mathrm{mol}$. The soft product impulse approximation value of $37 \mathrm{kcal} / \mathrm{mol}$ is fairly close to this average energy. By contrast, for reaction (R3), the translational energy would be predicted to be $\sim 80.9 \mathrm{kcal} / \mathrm{mol}$.

It is worth noting in passing that another channel is capable of explaining some of our findings-reaction (R7). However, this reaction was ruled out for several reasons.

$$
\mathrm{CH}_{3} \mathrm{~N}-\mathrm{N} \equiv \mathrm{N} \rightarrow \mathrm{CH}_{2} \mathrm{~N}+\mathrm{N}_{2} \mathrm{H} \text {. }
$$

First, $\mathrm{N}_{2} \mathrm{H}$ is an unstable species with a very short lifetime ${ }^{25}$ and would not be detected. Furthermore, $\mathrm{N}_{2} \mathrm{H}$ has a relatively low ionization potential [around $7.8 \mathrm{eV}$ (Ref. 26)]. In experiments done above the ionization potential for $\mathrm{N}_{2} \mathrm{H}$ but below the ionization potential for $\mathrm{CH}_{2} \mathrm{NH}$, we observed no signal. We also rule out the possibility that $\mathrm{N}_{2}$ is formed in an excited electronic state. There is not enough energy available at $248 \mathrm{~nm}$ to produce nitrogen in an excited electronic state.

While the energy release of the $\mathrm{N}_{2}$ elimination channel is easily explained by the formation of ${ }^{1} \mathrm{CH}_{3} \mathrm{~N}$, it is noteworthy that only very little signal is seen at $m / z=29$ in comparison to the signal at $m / z=28$. Likewise, the signal magnitude observed at $m / z=27$ is much larger than that at $m / z=29$. We can also rule out that the residual $m / z=29$ signal is due to nitrogen isotope $\left({ }^{15} \mathrm{~N}-{ }^{14} \mathrm{~N}\right)$ since we observe the $m / z=29$ signal at ionization potentials as much as $3.5 \mathrm{eV}$ below that of molecular nitrogen. These observations suggest that the majority of the initially formed ${ }^{1} \mathrm{CH}_{3} \mathrm{~N}$ decomposes during the $10^{-4} \mathrm{~s}$ flight time to the detector. The first step in this decomposition is certainly the $1,2-\mathrm{H}$-atom shift to form highly internally excited methanimine,

$$
\mathrm{H}_{3} \mathrm{C}-\mathrm{N} \rightarrow \mathrm{H}_{2} \mathrm{C}=\mathrm{NH} \quad \text { (isomerization). }
$$

If we were to assume that the departing $\mathrm{N}_{2}$ carried no internal energy, the $P\left(E_{T}\right)$ for $\mathrm{N}_{2}$ loss (Fig. 2) would imply that all of the hot methanimine exceeds the spin-allowed barrier to dissociation forming reactions (R4) and (R5). This may be an indication that the $\mathrm{N}_{2}$ can, at least with a small probability, be produced with more that $64 \mathrm{kcal} / \mathrm{mol}$ of internal energy. As we have no data on the $\mathrm{N}_{2}$ internal energy distribution we cannot rule this possibility out. However, we point out that this would be an unusual result. It may also be possible that some highly internally excited methanimine formed above the $\mathrm{HNC}+\mathrm{H}_{2}$ and $\mathrm{H}_{2} \mathrm{C}=\mathrm{N}+\mathrm{H}$ dissociation barrier, may survive the $10^{-4} \mathrm{~s}$ flight time, due to incomplete intramolecular vibrational randomization (IVR). While there are many examples where incomplete IVR leads to lifetimes 
less than the statistical expectation, it is also possible that a larger than expected lifetime could be observed, if the $\mathrm{N}-\mathrm{H}$ and $\mathrm{C}-\mathrm{H}$ bond stretching motions are not well coupled to the other modes of the molecule.

We comment that it is unclear from these experiments whether triplet surfaces play any role in this dissociation process. In similar small molecules, such as $\mathrm{HN}_{3}$, the singlet channel is strongly favored as soon as the barriers for spin-allowed dissociation are exceeded. ${ }^{7}$ Another welldocumented example that supports this statement is the competition between spin-allowed and spin-forbidden dissociation in ketene $\mathrm{H}_{2} \mathrm{C}=\mathrm{C}=\mathrm{O}^{27}$ While it is reasonable to postulate that triplet states play some role in these experiments, their presence is not required to explain our data.

On the other hand, there is evidence from other work that speaks in favor of some triplet dissociation. First, the triplet state of methylnitrene has been seen in previous experiments, ${ }^{2}$ however, those experiments were done in an environment where collisions could play a significant role in intersystem crossing and it is less clear if these are primary channels. If the dissociation were occurring on the triplet surface, we would expect to see some kinetic energy release in the secondary dissociation reaction (R4); however, we see no measurable kinetic energy release.

The synchrotron light's tunability allows us to clearly distinguish the dynamics of HNC and HCN formation and to rule out substantial interconversion between the two isomers after they are formed. While it may seem strange that isomerization between $\mathrm{HCN}$ and HNC does not occur in measurable quantities, it should not. First, it is possible that the two products are not formed above the isomerization barrier. Furthermore, the $\mathrm{HNC} / \mathrm{HCN}$ isomerization is a quantum mechanical isomerization system. Thus, whatever quantum states of HCN/HNC are formed in the photolysis, they are eigenstates and thus do not evolve in time. Furthermore, a rigorous study of accurate $\mathrm{HCN} / \mathrm{HNC}$ vibrational wave functions has shown that even above the barrier to isomerization the vast majority of vibrational states are localized over one of the two bonding wells and can be thought of as energized $\mathrm{HCN}$ or $\mathrm{HNC}^{28}$ As described above there are two components in the $m / z=27 \mathrm{TOF}$, Fig. 3. Both peaks can be fitted using the secondary dissociation analysis program ANALMAX. ${ }^{17}$ The presence of a significant amount of signal below the ionization potential for $\mathrm{HCN}$ proves that $\mathrm{HNC}$ (whose ionization potential is lower than $\mathrm{HCN}$ at $12.5 \mathrm{eV}$ ) and $\mathrm{HCN}$ are both formed in the decomposition of methanimine. Our observations lead us to conclude that two dissociation mechanisms are operative-one that leads to HNC through 1,1- $\mathrm{H}_{2}$ elimination and one that yields $\mathrm{HCN}$ through subsequent simple bond rupture loss of hydrogen atoms.

Figure 6 shows that HNC formation by the 1,1 elimination of $\mathrm{H}_{2}$ from methanimine would be expected to give rise to a large translational energy release as the exit barrier is about $70 \mathrm{kcal} / \mathrm{mol}$. While all $P\left(E_{T}\right)$ 's obtained from secondary dissociation analysis should be considered approximate, our observation of a faster channel leading to a low IP form of neutral mass 27 product is compelling and consistent with the assigned reaction mechanism.
In contrast to $\mathrm{HNC}, \mathrm{HCN}$ is formed by subsequent simple bond ruptures from the $\mathrm{CH}_{2} \mathrm{NH}$ fragment. The energy diagram (Fig. 6) helps explain why sequential H-atom loss leading to $\mathrm{HCN}$ would lead to translationally less excited products. First of all, there is much less available energy for this channel compared to the HNC channel, as $104 \mathrm{kcal} / \mathrm{mol}$ is required to dissociate the $\mathrm{H}_{2}$ molecule in this case. This, as well as the small or nonexistent exit barrier for the $\mathrm{H}$-atom elimination steps, prevents the HCN from becoming translationally excited.

Finally, we remark that the relative amounts of HNC and $\mathrm{HCN}$ are comparable in the observed data. We make no further attempts to quantify this statement due to the many difficult experimental factors over which we have no control.

\section{CONCLUSION}

Photolysis of methylazide at $248 \mathrm{~nm}$ has been performed and the photofragments have been analyzed using tunable synchrotron-radiation-based photoionization as well as measurements of product translational energy. Only one primary channel was observed, producing ${ }^{1} \mathrm{CH}_{3} \mathrm{~N}$ and $\mathrm{N}_{2}$. The exceptionally low translation energy release leads us to conclude that the initial products are the singlet methylnitrene reported previously by Travers et al. ${ }^{10}$ This species rapidly isomerizes to methanimine, $\mathrm{H}_{2} \mathrm{C}=\mathrm{N}-\mathrm{H}$, gaining a large amount of internal energy in the process, and then undergoes further unimolecular dissociation. Two such channels were observed: 1, 1- $\mathrm{H}_{2}$ elimination to obtain $\mathrm{HNC}$ and $\mathrm{N}-\mathrm{H}$ bond rupture forming $\mathrm{CH}_{2} \mathrm{~N}$ and subsequent $\mathrm{C}-\mathrm{H}$ bond rupture leading to $\mathrm{HCN}$.

\section{ACKNOWLEDGMENTS}

We thank several groups who made this experiment possible. Jeff Bode and Alex Lippert were instrumental in helping us synthesize our methylazide sample. We want to thank the hardworking and dedicated staff of the National Synchrotron Radiation Research Center in Taiwan for all the support they provided us in performing these experiments. As well, we would also like to thank the National Synchrotron Radiation Research Center for allowing us the beam time to perform our experiments. We also acknowledge the Air Force Office of Scientific Research (under Grant No. FA9550-041-0057) and Academia Sinica for providing funding for this project. One of the authors (A.M.W.) would like to acknowledge Yuan T. Lee for the profound influence on his professional and personal development. This paper is dedicated to him.

${ }^{1}$ H. R. Shang, C. Yu, L. M. Ying, and X. S. Zhao, Chem. Phys. Lett. 236, 318 (1995).

${ }^{2}$ L. M. Ying, Y. Xia, H. R. Shang, X. S. Zhao, and Y. Q. Tang, J. Chem. Phys. 105, 5798 (1996); Acta Physico-Chimica Sinica 11, 961 (1995).

${ }^{3}$ C. L. Currie and B. D. Darwent, Can. J. Chem. 41, 1552 (1963).

${ }^{4}$ N. Getoff, R. Laupert, and Rn. Schindle, Zeitschrift Fur Physikalische Chemie 70, 70 (1970).

${ }^{5}$ M. W. Chase, J. Phys. Chem. Ref. Data 27, I (1998).

${ }^{6}$ D. W. Rogers and F. J. McLafferty, J. Chem. Phys. 103, 8302 (1995).

${ }^{7}$ A. Teslja, B. Nizamov, and P. J. Dagdigian, J. Phys. Chem. A 108, 4433 (2004).

${ }^{8}$ M. T. Nguyen, D. Sengupta, and T. K. Ha, J. Phys. Chem. 100, 6499 (1996). 
${ }^{9}$ J. F. Arenas, J. I. Marcos, J. C. Otero, A. Sanchez-Galvez, and J. Soto, J. Chem. Phys. 111, 551 (1999).

${ }^{10}$ M. J. Travers, D. C. Cowles, E. P. Clifford, G. B. Ellison, and P. C. Engelking, J. Chem. Phys. 111, 5349 (1999).

${ }^{11}$ C. R. Kemnitz, G. B. Ellison, W. L. Karney, and W. T. Borden, J. Am. Chem. Soc. 122, 1098 (2000).

${ }^{12}$ D. Imre, J. L. Kinsey, A. Sinha, and J. Krenos, J. Phys. Chem. 88, 3956 (1984).

${ }^{13}$ H. Bock and R. Dammel, Angew. Chem., Int. Ed. Engl. 26, 504 (1987).

${ }^{14}$ A. Hassner, M. Stern, H. E. Gottlieb, and F. Frolow, J. Org. Chem. 55, 2304 (1990).

${ }^{15}$ J. J. Lin, Y. Chen, Y. Y. Lee, Y. T. Lee, and X. M. Yang, Chem. Phys. Lett. 361, 374 (2002).

${ }^{16}$ U. Even, J. Jortner, D. Noy, N. Lavie, and C. Cossart-Magos, J. Chem. Phys. 112, 8068 (2000)

${ }^{17}$ A. M. Wodtke, Ph.D. thesis University of California, Berkeley, 1986.

${ }^{18}$ M. D. Barry and P. A. Gorry, Mol. Phys. 52, 461 (1984).

${ }^{19}$ W. A. Chupka and C. Lifshitz, J. Chem. Phys. 48, 1109 (1968).
${ }^{20}$ G. Bieri and B. O. Jonsson, Chem. Phys. Lett. 56, 446 (1978).

${ }^{21}$ C. Fridh and L. Asbrink, J. Electron Spectrosc. Relat. Phenom. 7, 119 (1975).

${ }^{22}$ A. M. Wodtke, E. J. Hintsa, and Y. T. Lee, J. Phys. Chem. 90, 3549 (1986).

${ }^{23}$ E. J. Hintsa, A. M. Wodtke, and Y. T. Lee, J. Phys. Chem. 92, 5379 (1988).

${ }^{24}$ S. J. Riley and K. R. Wilson, Faraday Discuss. 53, 132 (1972).

${ }^{25}$ S. P. Walch, J. Chem. Phys. 93, 2384 (1990).

${ }^{26}$ N. Wiberg, G. Fischer, and H. Bachhuber, Z. Naturforsch., B: Chem. Sci. 34, 1385 (1979).

${ }^{27}$ C. G. Morgan, M. Drabbels, and A. M. Wodtke, J. Chem. Phys. 105, 4550 (1996); Abstr. Pap. - Am. Chem. Soc. 212, 10 (1996); J. Chem. Phys. 104, 7460 (1996); M. Drabbels, C. G. Morgan, D. S. McGuire, and A. M. Wodtke, ibid. 102, 611 (1995).

${ }^{28}$ T. Barger, A. M. Wodtke, and J. M. Bowman, Astrophys. J. 587, 841 (2003). 